\title{
Bronchial lability and skin reactivity in siblings of asthmatic children
}

\author{
C M VERITY, B VANHEULE, F CARSWELL, AND A O HUGHES \\ Departments of Child Health and Community Medicine, University of Bristol
}

SUMmARY Seventy five children with asthma ( 42 boys and 33 girls; age range 4 years 2 months to 15 years) and 75 of their siblings ( 37 boys and 38 girls; age range 4 years 3 months to 17 years 8 months) were studied to elucidate the mechanisms involved in the increased prevalence of asthma in boys, a prevalence that tends to disappear after puberty. Immediate cutaneous hypersensitivity to five allergens and maximum fall in peak expiratory flow rate after six minutes of treadmill running (bronchial lability) were determined in patients and siblings.

There was no significant difference between boys and girls in skin test reactivity to single or multiple allergens in the sibling group. The percentage fall in peak expiratory flow rate after exercise was significantly greater in male than in female siblings and when a positive test was defined as a fall after exercise of either $10 \%$ or $15 \%$ of the rate before exercise the number of positive tests was significantly greater in boys. The results suggest that more boys than girls in this age group have asthma because their bronchial lability is greater, and not because more boys are atopic.

Community studies show that asthma is more common in boys than in girls. ${ }^{12}$ Morrison Smith ${ }^{3}$ found that in Birmingham school children aged 5 and 6 years the boy:girl ratio was $2 \cdot 5: 1$. There was a subsequent fall in prevalence in the boys so that in 13 to 15 years olds the boy:girl ratio had fallen to 1.6:1. Martin et al ${ }^{4}$ in Melbourne found that the ratio of boys to girls in a group of severe asthmatics was 4:1 at 14 years of age; this preponderance among boys was not seen at age 21 years because improvement in girls was less than in boys. Crawford and Beedham ${ }^{5}$ found a change from male to female predominance between 14 and 21 years of age.

General practitioners ${ }^{56}$ reported seeing more young boys than young girls with asthma. In the asthma clinic at the Bristol Royal Hospital for Sick Children during the $71 / 2$ years from January 1975 until June 1983, 796 new patients were seen-514 boys and 282 girls, a boy:girl ratio of $1 \cdot 8: 1$.

The aim of this study was to determine whether the increased prevalence of asthma in boys is associated with increased bronchial lability or with increased immediate cutaneous hypersensitivity as shown by skin testing. We did this by investigating the siblings of children attending our asthma clinic. We used the term 'bronchial lability' to describe the fall in peak expiratory flow rate that follows treadmill exercise in some subjects.

\section{Patients and methods}

We studied 75 children attending our asthma clinic together with the nearest sibling in age to the clinic patient, irrespective of sex. We asked if either child had suffered allergic conjunctivitis, rhinitis, or eczema and if the sibling had ever been diagnosed as having asthma or wheezy bronchitis. We also asked if any medication had been prescribed for these conditions. Skin prick (immediate hypersensitivity) testing was performed with the same five Bencard test solutions for each patient-house dust (solution No 3201), house dust mite (solution No 2801), mixed grass pollen (solution No 4100), timothy grass pollen (solution No 4110), and cat fur (solution No $3204)$ - plus a positive histamine control (1\% solution) and a negative control (solution No 1908). The maximum wheal diameter at 15 minutes was measured. A positive skin test was defined as one in which the wheal diameter was greater than $3 \mathrm{~mm}$.

The highest value of three forced expiratory manoeuvres performed on the Vitalograph spirometer was used to calculate the forced vital capacity and the forced expiratory volume in one second. 
The peak expiratory flow rate was recorded as the highest result from three forced expirations into the Wright peak expiratory flowmeter. Intersubject comparisons involved the conversion of results to the percentage of predicted normal for height and sex. ${ }^{7}$

Patients and siblings underwent exercise testing. After peak expiratory flow rate and pulse rate were recorded, the subject ran on a treadmill for six minutes, aiming to reach a pulse rate of 160 per minute or more after exercise. Children aged 6 years or less ran on $10^{\circ}$ of slope at 3.5 miles per hour; older children on $15^{\circ}$ of slope at the same speed. Peak expiratory flow rate was recorded one, five, 10,15 , and 20 minutes after exercise and the maximum fall in peak flow after exercise was recorded. A positive exercise test was usually defined as one in which the maximum fall in peak expiratory flow rate after exercise was $10 \%$ or more of the value before exercise. This is our definition of a 'positive' test unless .otherwise stated. Differences between boys and girls were tested using the Mann-Whitney non-parametric test and $\chi^{2}$ test. Patients were compared with siblings using the Wilcoxon matched pairs test.

\section{Results}

Family history. We studied a patient and a sibling from each of 75 families. In $12 \%$ of the families both parents had atopic symptoms (asthma, eczema, allergic rhinitis, allergic conjunctivitis, or urticaria). In $16 \%$ of families the mother was the only parent affected and in $16 \%$ the father was the only parent affected. In $47 \%$ of families the child attending our clinic was the only sibling with atopic symptoms. In $36 \%$ of families one other child had atopic symptoms and in $16 \%$ two other children were affected. The number of children per family studied was mean (SD) $2.49(0.93)$.

Clinic patients. There was no significant difference between the ages of the 42 boys (age range 4 years 3 months to 14 years 4 months; median age 9 years 1 month) and the 33 girls (age range 4 years 2 months to 15 years; median age 8 years 8 months). All were taking regular asthma medication and $84 \%$ of them suffered with episodes of wheeze at least monthly. Asthma had developed before 2 years of age in $49 \%$. The prevalence of allergic disease as reported by the parents is given in Table 1 .

Siblings. There was no significant difference between the ages of the 37 boys (age range 4 years 3 months to 15 years 3 months; median age 10 years 4 months) and the 38 girls (age range 6 years 1 month
Table 1 Results of history taking in the children studied

\begin{tabular}{|c|c|c|c|c|}
\hline & $\begin{array}{l}\text { All clinic } \\
\text { patients }\end{array}$ & $\begin{array}{l}\text { All } \\
\text { siblings }\end{array}$ & $\begin{array}{l}\text { Male } \\
\text { siblings }\end{array}$ & $\begin{array}{l}\text { Female } \\
\text { siblings }\end{array}$ \\
\hline Total No & 75 & 75 & 37 & 38 \\
\hline Asthma* & & & & \\
\hline No $(\%)$ & $75(100)$ & $11(15)$ & $7(19)$ & $4(10)$ \\
\hline Wheezy bronchitis* & & & & \\
\hline No $(\%)$ & \multicolumn{2}{|c|}{ Not asked $: 12^{\dagger}(16)$} & $8(22)$ & $4(10)$ \\
\hline Allergic rhinitis & & & & \\
\hline No $(\%)$ & $50(67)$ & $20(27)$ & $11(30)$ & $9(24)$ \\
\hline Allergic conjunctivitis & & & & \\
\hline No $(\%)$ & $43(57)$ & $17(23)$ & $9(24)$ & $8(21)$ \\
\hline Eczema & & & & \\
\hline No $(\%)$ & $34(45)$ & $17(23)$ & $10(27)$ & $7(18)$ \\
\hline Urticaria & & & & \\
\hline No $(\%)$ & $20(27)$ & $5(7)$ & $2(5)$ & $3(8)$ \\
\hline
\end{tabular}

* For both of these diagnoses we give the conclusion reached by the doctor(s previously attending the child. The other diagnoses were made by us after assessment of symptoms reported at interview.

Three of these siblings had also been diagnosed as having asthma. Altogethe 20 siblings had been diagnosed as suffering from either asthma or wheezyo bronchitis, or both.

to 17 years 8 months; median age 8 years 6 months). $\vec{\sim}$ Health was reported as 'good' in $89 \%$ of the siblings $\mathbb{D}$ but $11(15 \%)$ had been diganosed as asthmatic, $12 \%$ $(16 \%)$ as suffering from wheezy bronchitis, and $\stackrel{\mathbb{3}}{3}$ three (four per cent) as suffering from both asthma and wheezy bronchitis. Eight were on medication seven were taking salbutamol intermittently and obe sodium chromoglycate regularly. Fifteen of 37 bo ${ }^{+}$ had already been diagnosed as suffering from eith⿳亠丷厂巾 asthma or wheezy bronchitis compared with eight 38 girls (Table 1).

\section{Sex differences}

Resting respiratory function

The forced expired volume in one second and peak expiratory flow rate measured before exercise were $\frac{}{\supset}$ significantly lower in patients than in the siblings. When the different sexes were compared in each group, however, there were no significant differ-气ू ences between boys and girls (Table 2).

\section{Bronchial lability}

The maximum percentage fall in peak flow after exercise was compared in boys and girls (Table 2 을 and Figure). In the sibling group the mean fall was $16.4 \%$ in the boys and $9.7 \%$ in the girls. The difference was statistically significant $(\mathrm{P}<0 \cdot 05)$. There was no such significant difference between $N$ the sexes in the clinic patients. If we defined a positive exercise test as one in which there was a fallo in peak expiratory flow rate after exercise equal to $\omega$ or greater than $10 \%$ of the value before exercise, $20 \%$ of the 37 male siblings had positive tests; only 10 of the 38 female siblings had positive tests. (A significant difference between the sexes, $\mathrm{P}<0 \cdot 05$.) If we defined a positive test as one in which there was $a \frac{0}{0}$ 
Table 2 Initial respiratory function and exercise induced bronchial lability

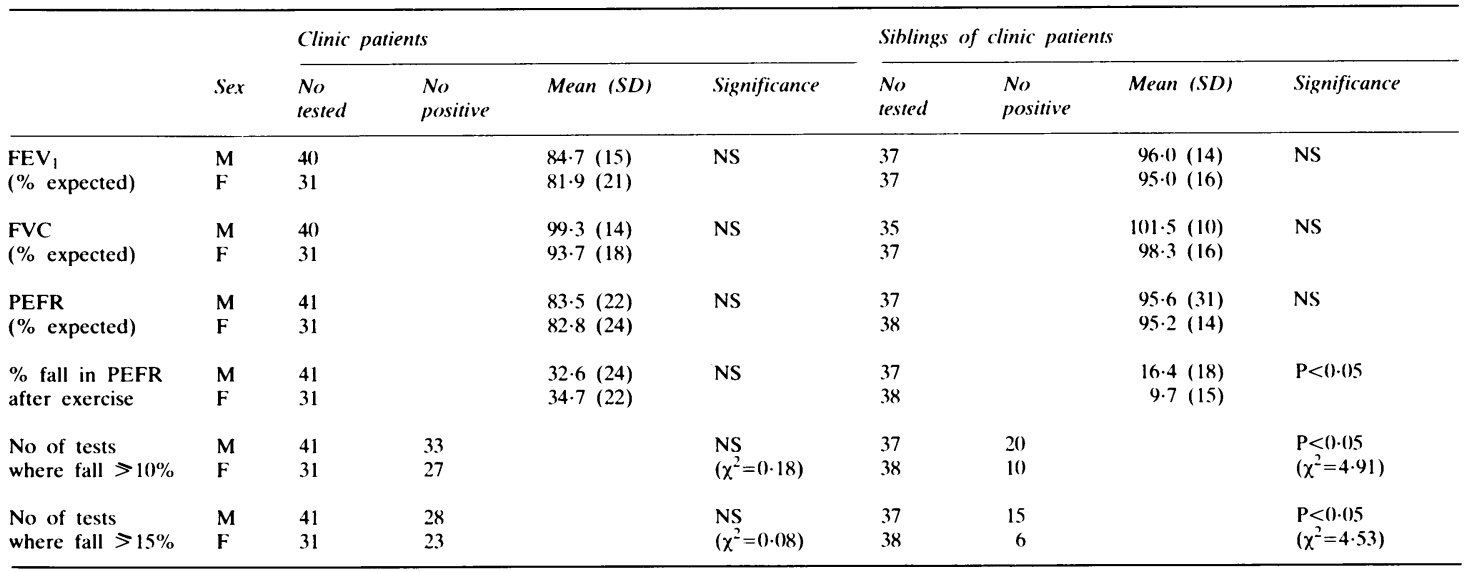

$\mathrm{FEV}_{1}=$ forced expiratory volume in $1 \mathrm{sec} ; \mathrm{FVC}=$ forced vital capacity: PEFR=peak expiratory flow rate; NS=not significant.

fall in peak expiratory flow rate after exercise equal to or greater than $15 \%$ of the value before exercise, 15 of 37 boys but only six of 38 girls were positive (still a significant difference between the sexes $\mathbf{P}<0.05$ ). In the clinic patients there was no significant sex difference in the number of positive exercise tests.

If we excluded all the siblings who had already been diagnosed as suffering from either asthma or wheezy bronchitis, or both, the results were as follows. For those positive tests defined as a fall of $10 \%$ or more after exercise, 10 of $24(42 \%)$ of the remaining male siblings had positive skin tests compared with five of $31(16 \%)$ of the remaining female siblings. For positive tests defined as a fall after exercise of $15 \%$ or more, five of $24(21 \%)$ of the remaining male siblings had positive skin tests compared with two of $31(6 \%)$ of the remaining female siblings. Although the proportion of affected boys remained greater, the boy-girl difference in bronchial reactivity failed to reach statistical significance after removing the siblings previously diagnosed as having either asthma or wheezy bronchitis, or both.

The possibility that the female siblings did not exercise as hard as the boys was examined. The median pulse rate immediately after exercise was 168 per minute in the girls and 160 in the boys. Ten of the 17 siblings who failed to achieve a pulse rate of 160 after exercise were boys, of whom six had positive exercise tests; seven were girls, of whom only two had positive exercise tests. Thus, even in the siblings that did not exercise as hard more boys had positive exercise tests.

Results could have been biased by an uneven distribution of the sexes, however, the 42 male clinic patients had 20 male and 22 female siblings, while the 33 female patients had 17 male and 16 female siblings, so the distribution was even. Also there were no significant differences in the proportion of positive exercise tests between brothers of male patients and brothers of female patients. It therefore seemed unlikely that the sex differences found were a result of bias in the selection of subjects.

\section{Skin tests}

Single antigens. We compared both wheal diameter and number of positive tests. In the patients the mean wheal diameters on testing with house dust mite and house dust were significantly greater in boys than in girls $(\mathrm{P}<0.05$ for both antigens). In the siblings there were no significant differences between the sexes for any of the five antigens used.

Multiple antigens. In the clinic patients, 30 of 40 boys and 16 of 31 girls tested had more then one positive skin test; 19 of 40 boys and 13 of 31 girls had more than two positive skin tests. In the siblings, 15 of 37 boys and 13 of 37 girls had more than one positive skin test; 12 of 37 boys and eight of 37 girls had more than two positive skin tests. In neither clinic patients nor siblings was there a statistically significant boy-girl difference in the proportion of patients with multiple positive skin tests, whether we defined this as being more than one positive test or more than two positive tests.

Siblings-relation between clinical history and exercise tests

Most (15) of the 20 siblings with previously di- 
874 Verity, Vanheule, Carswell, and Hughes

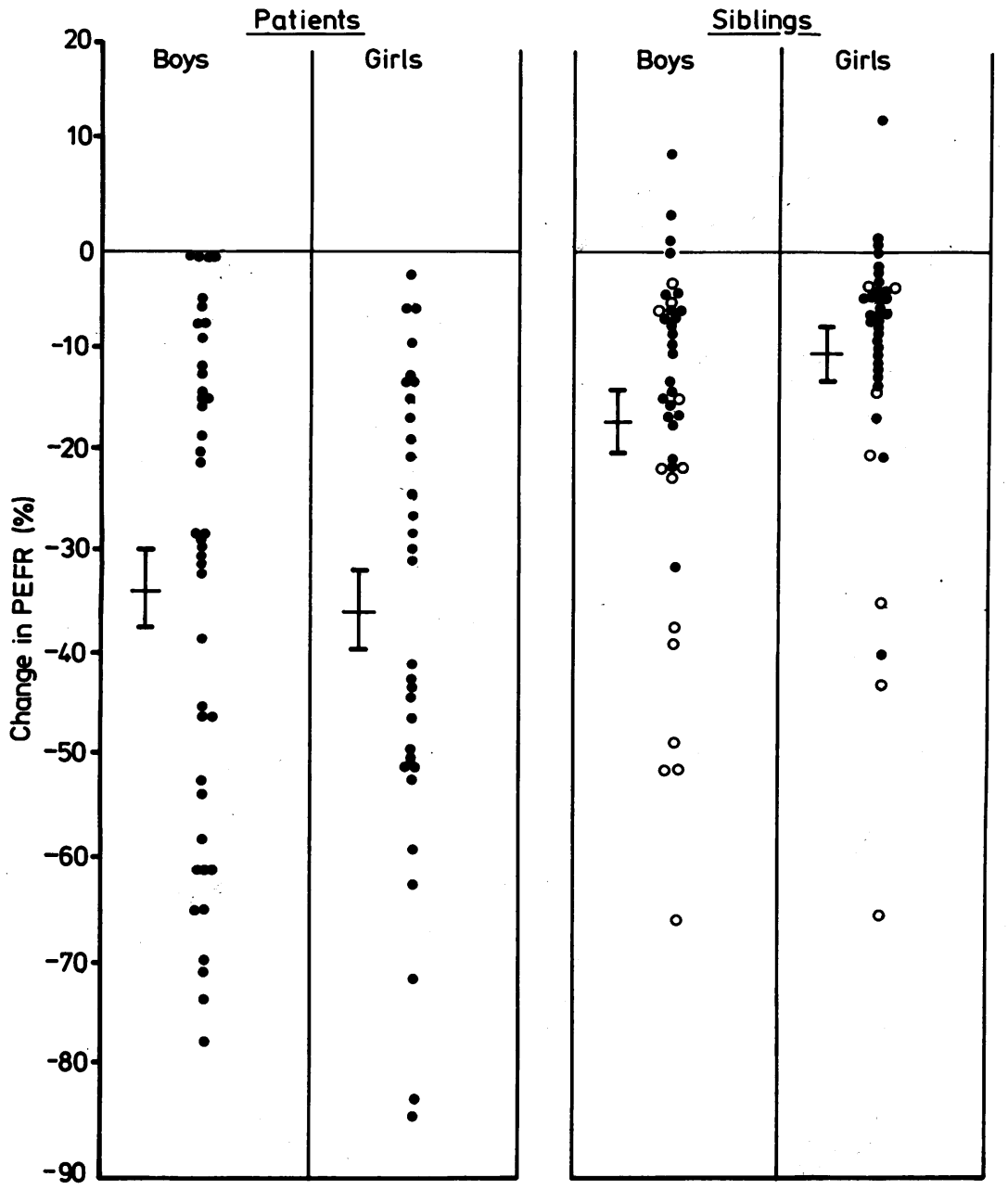

Figure The maximum percentage change in peak expiratory flow rate (PEFR) after exercise is shown for the clinic patients and their siblings. Those siblings previously diagnosed as suffering from either asthma or wheezy bronchitis, or both, are represented by open circles. (Bars show mean $\pm S E M)$.

Results shown for only 41 male patients (one too wheezy for testing) and 31 female patients (two too wheezy for testing).

agnosed asthma or wheezy bronchitis had positive exercise tests (10 of 13 boys; five of seven girls), however, only 15 of the 30 siblings who had positive exercise tests had already been diagnosed as having asthma or wheezy bronchitis-10 of 20 boys and five of 10 girls-(that is no sex difference in the proportion diagnosed). Sixteen of the 30 patients with a history of atopy (allergic conjunctivitis, allergic rhinitis, eczema, or urticaria; excluding asthma and wheezy bronchitis) had a positive exercise test -11 of 15 boys and five of 15 girls.
Siblings-relation between positive skin tests and?ำ bronchial lability

Only 13 of the 32 siblings with at least one positive skin test had a history of asthma or wheezy N bronchitis-nine of 17 boys and four of 15 girls. Less than half of these 32 siblings had positive exercise 0 tests -10 of 17 boys and four of 15 girls. Conversely, $\omega$ only 15 of 30 patients with positive exercise tests hadO at least one positive skin test- 10 of 20 boys and fiveo of 10 girls. Thus, there was not a close correlation $\bar{\varnothing}$ between positive skin testing and positive exercise? testing in these patients. 


\section{Discussion}

Wheezy bronchitis and asthma. McNichol and Williams ${ }^{8}$ failed to find evidence that asthma and wheezy bronchitis were separate clinical entities and other authors ${ }^{9}{ }^{10}$ have suggested that there is a common genetic basis. In assessing the relevance of clinical history we have treated as one group those siblings with diagnoses of asthma and wheezy bronchitis. In many patients and siblings an initial diagnosis of 'wheezy bronchitis' had been changed to 'asthma' before referral to our clinic, and treatment with antibiotics had been changed to bronchodilators. In two families one child was attending our asthma clinic and being treated with bronchodilators for asthma while the other sibling was being treated by the general practitioner for 'bronchitis'. In both of these families we found that the exercise test in the sibling was strongly positive (greater than $15 \%$ fall in peak expiratory flow rate after exercise), and both children in the family had similar symptoms.

Skin testing. Although it is known ${ }^{8}$ that those children with more severe asthma react more strongly to more allergens on skin testing than those with mild asthma, allergic factors are not the only cause of asthmatic attacks. König and Godfrey ${ }^{11}$ found that in relatives of asthmatic children $60 \%$ of subjects with positive skin tests ('atopics') had normal bronchial lability implying that atopy alone did not produce asthma. A similar proportion $(56 \%)$ of our siblings with at least one positive skin test had exercise tests within the normal range. We differed from König and Godfrey ${ }^{11}$ in that we did not find a sex difference in skin test positivity in the siblings. They found that groups with multiple positive skin tests showed a preponderance of boys. We agree with Davis ${ }^{2}$ who found that the sex difference in the prevalence of asthma was not reflected in sex differences in multiple sensitivity to skin allergens. Like McNichol and Williams, ${ }^{8}$ Davis suggested that atopy 'may not be the main determinant' of wheeze. The skin test reaction to specific allergens correlates well, however, with the bronchial reactivity to those allergens as determined by bronchial provocation tests. $^{12}$

Bronchial lability. Silverman and Anderson ${ }^{13}$ showed that $70 \%$ of asthmatic children had a significant fall in peak expiratory flow rate after treadmill running. They suggested that this increased lability was a feature of asthmatics and that it was not closely related to the clinical condition in individual patients. The non-specific irritability of the airways which is measured by the exercise test is now recognised to be the same irritability which is measured by exposing the airways to other irritants such as histamine or methacholine ${ }^{14}$ Balfour-Lynn et $a l^{15}$ found that exercise induced bronchial lability was a sensitive indicator of clinical asthma which disappeared when the patient was symptom free. It may be difficult, however, to be sure that children are asymptomatic. We tested many children who complained little about their symptoms but who had clear evidence of exercise induced bronchial lability. There was much variation in the emotional distress exhibited by different children as a result of the same measured fall in peak flow after exercise. We found that only half of the siblings with positive running tests had been diagnosed as having asthma (the same proportion in boys as in girls).

Sex difference in the prevalence of bronchial lability. We have shown increased bronchial lability in the male siblings of asthmatics compared with the female siblings. There was no detectable sex difference in the reactivity of their skin to five different allergens. Although the female siblings seemed slightly younger (median age 8 years and 6 months) than the boys (median age 10 years and 4 months), this difference was not statistically significant. The preponderance of boys with asthma falls with increasing age ${ }^{3-5}$ perhaps because of greater clinical improvement in the boys. It would therefore be anticipated that the slightly older median age of the boys in our study would, if anything, have tended to reduce the proportion of boys with bronchial lability and asthma. The increased bronchial lability we found in the boys is therefore unlikely to have been produced by an age difference between the boys and the girls.

In another study which uses identical techniques (Carswell et al 1983, unpublished) we found that the coefficient of variation for exercise testing in school children who have a mean fall of seven per cent in peak exercise flow rate is $67 \%$. Our coefficient of variation for skin testing was $18 \%$ in a subject with mean wheal diameter of $7.4 \mathrm{~mm}$ in response to house dust mite Bencard solution No 2801. The greater variability in exercise testing might suggest that it would be more difficult to show a sex difference in bronchial lability than in skin reactivity. The fact that the opposite was the case reassures us that there is truly greater bronchial reactivity in the male siblings of the asthmatic patients.

Conclusion. The increased prevalence of asthma in boys might be explained by one or more of the following: 
(1) Boys might normally exercise more vigorously than girls and therefore provoke more symptoms This was not the case in the siblings- the median pulse rate immediately after exercise was higher in the girls than in the boys. Even in those siblings who did not exercise as hard, more boys than girls had positive exercise tests.

(2) Parents might be more concerned about symptoms in boys and therefore bring more boys to the attention of doctors

We did not find this-in the siblings with positive exercise tests there was no evidence that a greater proportion of boys than girls had previously been diagnosed as suffering from wheezy bronchitis or asthma.

(3) There might be a higher incidence of atopy in boys than in girls

We found no sex difference in the incidence of atopy in the siblings as determined by skin prick testing.

(4) There might be increased bronchial lability in boys

We obtained the sibling group in our study by rigidly selecting the sibling nearest in age to the clinic patient regardless of either the child's sex or whether he or she had already been diagnosed as suffering with asthma or wheezy bronchitis. We showed in this selected group that after the same amount of exercise there was a greater bronchial lability in the boys than in the girls.

In this group of siblings of asthma patients we found that more boys had been diagnosed as having either asthma or wheezy bronchitis, or both, than girls (13 boys $v$ seven girls). We showed increased bronchial lability in the boys compared with the girls but found no sex differences on skin testing. We suggest, therefore, that the increased prevalence of asthma in the sibling boys is more directly related to increased bronchial lability than to atopy. It may be that in the general population also the increased prevalence of asthma in boys is more directly related to increased bronchial lability than to a higher incidence of atopy.
We gratefully acknowledge the assistance of the nursing staff at the? Asthma Clinic, Bristol Children's Hospital in carrying out this study. B V was a British Council Scholar while engaged in this:work.

\section{References}

1 Peat JK, Woolcock AJ, Leeder SR, Blackburn CRB. Asthma and bronchitis in Sydney schoolchildren. I. Prevalence during
six year study. Am J Epidemiol 1980;1II:721-7.

2 Davis JB. Asthma and wheczy bronchitis in children. Clinê Allergy 1976;6:329-38.

3 Morrison Smith J. Prevalence and natural history of asthma in $\vec{\rho}$ schoolchildren. $\mathrm{Br}$ Med J 1961;i:711-3.

4 Martin AJ, McLennan LA, Landau LI, Phelan PD. The naturak $\vec{\omega}$ history of asthma to adult life. Br Med J 1980;ii:1397-400. O

5 Crawford WA, Beedham CG. The changing demographic్ pattern in asthma related to sex and age. A study of 13,651 ? patients on sodium chromoglycate (Intal). Med J Aus 1972;I:430-4.

6 Blair H. Natural history of childhood asthma. A 20 year follow up. Arch Dis Child 1977;52:613-9.

7 Polgar G, Promadhat V. Pulmonary function testing in children. Techniques and standards. Philadelphia: Saunders, 1971.

${ }^{8} \mathrm{McNichol} \mathrm{KN}$, Williams HE. Spectrum of asthma in children- II, allergic components. Br Med J 1973;iv:12-6.

${ }^{9}$ König P, Godfrey S. Exercise-induced bronchial lability and atopic status of families of infants with wheczy bronchitis. $\operatorname{Arch} \frac{}{\mathbb{D}}$ Dis Child 1973;48:942-6.

10 Sibbald B, Horn MEC, Greeg E. A family study of the genetic금 basis of asthma and wheezy bronchitis. Arch Dis Child $\stackrel{\mathbb{D}}{=}$ 1980;55:354-7.

11 König P, Godfrey S. Prevalence of excrcise-induced broncloal lability in familes of children with asthma. Arch Dis C ${ }^{\circ}+$ 1973;48:513-8.

12 Bryant DH, Burns MW, Lazarus L. The correlation betwe्छे skin tests, bronchial provocation tests and the serum level of FgE specific for common allergens in patients with asthma. Clin Allergy 1975;5:145-57.

13 Silverman M, Anderson SD. Standardization of exercise tests in $\frac{2}{\mathbb{D}}$ asthmatic children. Arch Dis Child 1972;47:882-9.

14 Souhrada JF, Buckley JM. Pulmonary function testing in $\overline{\overline{0}}$ asthmatic children. Pediatr Clin North Am 1976;23:249-78.

15 Balfour-Lynn L. Tooley M, Godfrey S. Relationship of exerciseinduced asthma to clinical asthma in childhood. Arch Dis Child $1981 ; 56: 450-4$.

Correspondence to Dr C M Verity, Department of Child Health. ำ Bristol Royal Hospital for Sick Children, St Michael's Hill, Bristol? BS2 8BJ.

Reccived 14 May 1984 